Open Scientist Handbook • OSH

\title{
The Congruent Scientist: Infinite play builds personal wisdom
}

\author{
Bruce R. Caron
}

Published on: Mar 10, 2021

DOI: $10.21428 / 8 b b b 7 f 85 . e 5 b 4 e e 3 b$

License: Creative Commons Attribution 4.0 International License(CC-BY 4.0). 


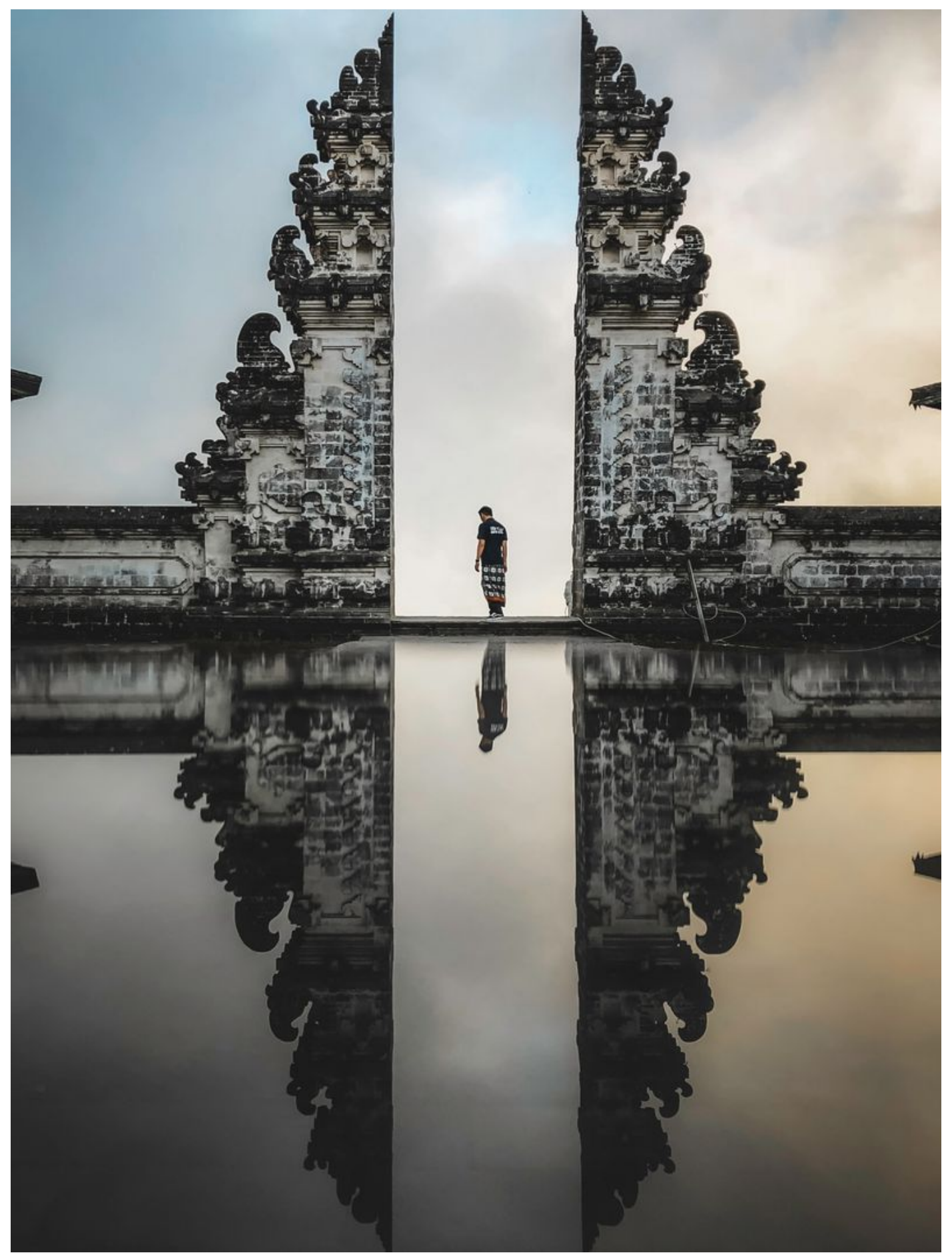




\section{The Congruent Scientist: Infinite play builds personal wisdom}

"Yet notoriously the cultivation of truthfulness, justice and courage will often, the world being what it contingently is, bar us from being rich or famous or powerful. Thus although we may hope that we can not only achieve the standards of excellence and the internal goods of certain practices by possessing the virtues and become rich, famous and powerful, the virtues are always a potential stumbling block to this comfortable ambition" (MacIntyre 1984).

"For us, activism in the academy springs from and serves the infinite game: it is action beyond the rules that calls us to take our intuitions, lived experience and observations of injustice and exclusion seriously. Academic activism aims to document, subvert and ultimately rewrite the rules of the finite games we currently live by, so that they make more sense to us as people seeking to give of our best to an endeavour ('the university') that we cannot help but believe in" (Harré, et al. 2017; emphasis added).

Alasdair MacIntyre's caveat rings true when applied to finite power games in and out of the academy. It's the same "nice guys finish last" logic that your academic advisor may have given you; "practical" advice that many in the academy have used as an alibi against sharing their data and methods openly. Open scientists know better. This logic exposes how the external goods of the neo-liberal market are crowding out the internal goods so vital to the success of science as a practice. Nicholas Gruen (Accessed February 21, 2020) puts it this way: "Here's the serpent in paradise. External goods are necessary, but, at the same time, in tension with internal goods. This is an ethical tension. The risk is always that the pursuit of external goods compromises the pursuit of internal goods, and thus the excellence of the practice."

Certainly, during the transition phase to open practices of Fierce Equality and Demand Sharing, there will still be finite games for external goods where the few consider themselves winners, and all others as losers. The hyper-competition for scarce external goods in the academy is not going to simply disappear on its own. Certain finite game strategies can also be helpful, for sharpening methodologies, say, or microfunding opportunities. So, some finite games will continue.

Today, dozens of open science endeavors have articulated alternative solution pathways for distributing external goods without supporting perverse incentives (Edwards and Roy 2017; Bartling and Friesike 2014). However, building alternative practices through intentional culture change takes time and effort. The open, infinite 
game of science treasures its abundant internal goods-including internal measures of recognition and modes of compensation-above money, fame, and glory. Something to remember when you have little of the latter.

One particular internal good in the academy happens when your work and your person become congruent - the practical wisdom of doing science you learn and apply to your research, and with your teammates. You will also find this useful in your personal life with friends and family.

\section{Background on the notion of congruence}

In 1961, the psychotherapist Carl Rogers compiled three decades of papers into the book On Becoming a Person. The main frame of the book describes his client-centric approach to psychotherapy, how he arrived at this and what he learned as a practitioner. Many of the articles read very much as blogs do today (and were unpublishable in the scientific journals for this reason). He then links this frame to other human endeavors. In particular, he looks to education and personal relations in organizations.

His main therapeutic process involves how the psychoanalyst as a person develops her own personhood by becoming more congruent (more about this in a minute) and then uses this congruence as a communication tool to open up the client to the process of becoming more congruent. The therapist is really only someone further along the same road to "becoming a person."

The process of becoming a person, of achieving more and wider congruence, and so having fewer and fewer defenses, brings the client to a better life, with less tension and fear, better communication with everyone, and new opportunities to explore each moment fully. For Rogers, congruence happens when one's real self (the one we all start out with-all infants are congruent-also the one we can shape with our own skills and the virtues we build) fully resembles one's ideal self (the one we acquire from social interactions with others).

Another way to look at this reveals the parallels between personal change and organizational change: the person moves away from managing their fears, and attempts at controlling the behavior of others, to governing their own growth: becoming more reflexive, open to self-examination, better able to handle conflict, and by this, becoming more resilient and capable of change. The very same pathway is how organizations can successfully change (Argyris 2004). The goal of congruence is also 
extremely well aligned with the goal of "becoming a scientist:" congruence unlocks intellectual creativity.

\section{Creativity in science is a self-therapeutic practice}

"The mainspring of creativity appears to be the same tendency which we discover so deeply as the curative force in psychotherapy-man's tendency to actualize himself, to become his potentialities....This tendency may be come deeply buried under layer after layer of encrusted psychological defenses; it may be hidden behind elaborate façades which deny its existence; it is my belief however, based on my experience, that it exists in every individual, and awaits only the proper conditions to be released and expressed. It is this tendency which is the primary motivation for creativity as the organism forms new relationships to the environment in its endeavor most fully to be itself" (Rogers 1961).

The ideal self represents the roles you acquire in order to play finite games in your life and career. The rules you follow may still be the same rules you determined in early childhood. So by now, you are really good at following; and far less capable of knowing why you do so. For example, in your academic position, you are "The Scientist." As Carse (1987) noted and Rogers might agree here, you have forgotten that you have the freedom to set aside your role. Quite the reverse: the role has become you. This is why you spend so much effort defending your ideal self/role, even (or especially) against your real self. How do you escape?

"[P]rogress in personal life and in group living is made in the same way, by releasing variation, freedom, creativity" (Rogers 1961). The creativity you invest in the infinite game of science builds the capacity you can use to release your real self from the roles you play in finite games. You acquire the mindset of an infinite player and become selfdirected toward congruence. As Rogers notes:

"[T]he individual who is open to his experience, and self-directing, is harmonious, not chaotic, ingenious rather than random, as he orders his responses imaginatively toward the achievement of his own purposes. His creative actions are no more a chaotic accident than was Einstein's development of the theory of relativity" (ibid).

Simon Sinek (2019) would add that your infinite player mindset is precisely what you need to succeed as a team member in $21^{\text {st }}$ Century science. 


\section{Open science and an open you}

How does the authenticity of doing science as an infinite game bleed over into your personal life? Can science really make you a "better person"? The skills you acquired to become a scientist, and the cultural practices of open science you are weaving into your work are tools you can use if you bring along the courage to seek change; "making courage part of your personal culture means you are always willing to keep making changes in your life until it is the life that you want and the life that you deserve. Courage in your life means you accept that there will be missteps-that constant and repeated change may be necessary, but that it is nothing to be ashamed of if it leads to a more fulfilling, positive outcome (Dudley 2018).

The intellectual tools of science, such as rigorous, reflexive curiosity, openness, and intellectual humility are available to the scientist for use in other circumstances. You can bring these skills home with you. The same kindness and humility you bring (one hopes) to your teaching and research can become an interactive style elsewhere.

\section{On becoming an organization}

"If things aren't going right, the first response is: let's make more rules, let's set up a set of detailed procedures to make sure that people will do the right thing. Give teachers scripts to follow in the classroom, so even if they don't know what they're doing and don't care about the welfare of our kids, as long as they follow the scripts, our kids will get educated. Give judges a list of mandatory sentences to impose for crimes, so that you don't need to rely on judges using their judgment....Impose limits on what credit card companies can charge in interest and on what they can charge in fees. More and more rules to protect us against an indifferent, uncaring set of institutions we have to deal with" (Barry Schwartz 2011 TED Talk; Accessed 02/17/2020).

In the Handbook's section on Learning Organizations, we discovered double-loop learning/governance. Double-loop governance maps directly into congruence at the organizational level: the so-called "ideal" organization being the first loop, and the real organization being the second loop. Instead of hiding the real organization behind the idealized intentions of the founder, or top-down rules and regulations derived from an imperious CEO or provost, double-loop governance makes the real organization available to every member. Each member has the same view and purview of the rules and roles, the values and the vision of the organization, and also an obligation to make these congruent with the everyday activities of the organization. Real change for the organization also requires its members—not just the CEO-to learn to use "valid 
information, informed choice, and vigilant monitoring of the implementation of the choice in order to detect and correct error" (Argyris 2004).

"Double-loop learning focuses on detecting and correcting errors in the designs of the master programs that underlie the routines. When this is the case, the attention is focused on changing the governing of the values, policies, and master programs that produced the routines in question in the first place. Double-loop learning is at the heart of the distinction, often made in the literature, between doing something right and doing the right thing" (Argyris 2004).

The notion that your organization can also be a therapeutic setting where members can learn to become more congruent may seem peculiar today, where management mainly promotes rule-governed compliance. Barry Schwartz tells us to stop already with the rules and use our everyday interactions to grow social and personal virtues:

“Rules and incentives don't tell you how to be a good friend, how to be a good parent, how to be a good spouse, or how to be a good doctor or a good lawyer or a good teacher. Rules and incentives are no substitutes for wisdom. Indeed, we argue, there is no substitute for wisdom. And so practical wisdom does not require heroic acts of self-sacrifice on the part of practitioners. In giving us the will and the skill to do the right thing - to do right by others-practical wisdom also gives us the will and the skill to do right by ourselves. (Barry Schwartz 2011 TED Talk; Accessed February 17, 2020).

Remember also that organizational "knowing" - the stock of sharable knowledge that defines your academic institution's main research resource-is a series of conversations between two or more people. Knowing cannot be stored, only generated anew as each conversation leverages the prior ones. Your organization's culture and governance sets up the circumstances at work where members can (or cannot) communicate effectively to share their insights and grow creativity. Mainly what they share is a specific, collective scientific ignorance.

"This [the shared ignorance in a scientific conversation] is knowledgeable ignorance, perceptive ignorance, insightful ignorance. It leads us to frame better questions, the first step to getting better answers. It is the most important resource we scientists have, and using it correctly is the most important thing a scientist does" (Firestein 2012). Using open science with an infinite play mindset, you can make your organization a place where each member can become more of a person. In return they will make your organization a better place in which to get science done. 


\section{Coda}

You've likely met one or more congruent scientists. Someone who has engaged you in conversation at a workshop or conference. You walk away thinking, "She is so open and intellectually humble, knows so much, and asks really great questions. She must be such fun to work with." You might have also sensed a wellspring of truthfulness, justice, and courage there. A corner of your ego might wonder what she thought of you. If you were engaged in infinite play with her, and not trying to win points, she probably noticed.

You may also have visited a congruent organization (or, with great luck, you've ended up working in one), and come away wondering how they manage to avoid all the administrative bullshit you deal with every day. How do they sustain that level of creative interactions? How come everybody felt safe enough to say those things out loud? What does one need to do to get a job there?

In the Earth sciences, there's a virtual organization called Earth Science Information Partners (ESIPfed.org). This is a great example of a congruent organization. A few years back, they hired an independent review organization to advise them on what they could do to improve. The report came back: sorry, everyone who knows you loves how you work right now. The reviewers were apologetic about not exposing problems to be fixed. ESIP has been a double-loop learning organization for two decades. It shows. Here's an introduction to their bi-yearly_gatherings.

The Open Scientist Handbook offers tools for you to become more congruent and to build congruent governance practices into your own academy home. 


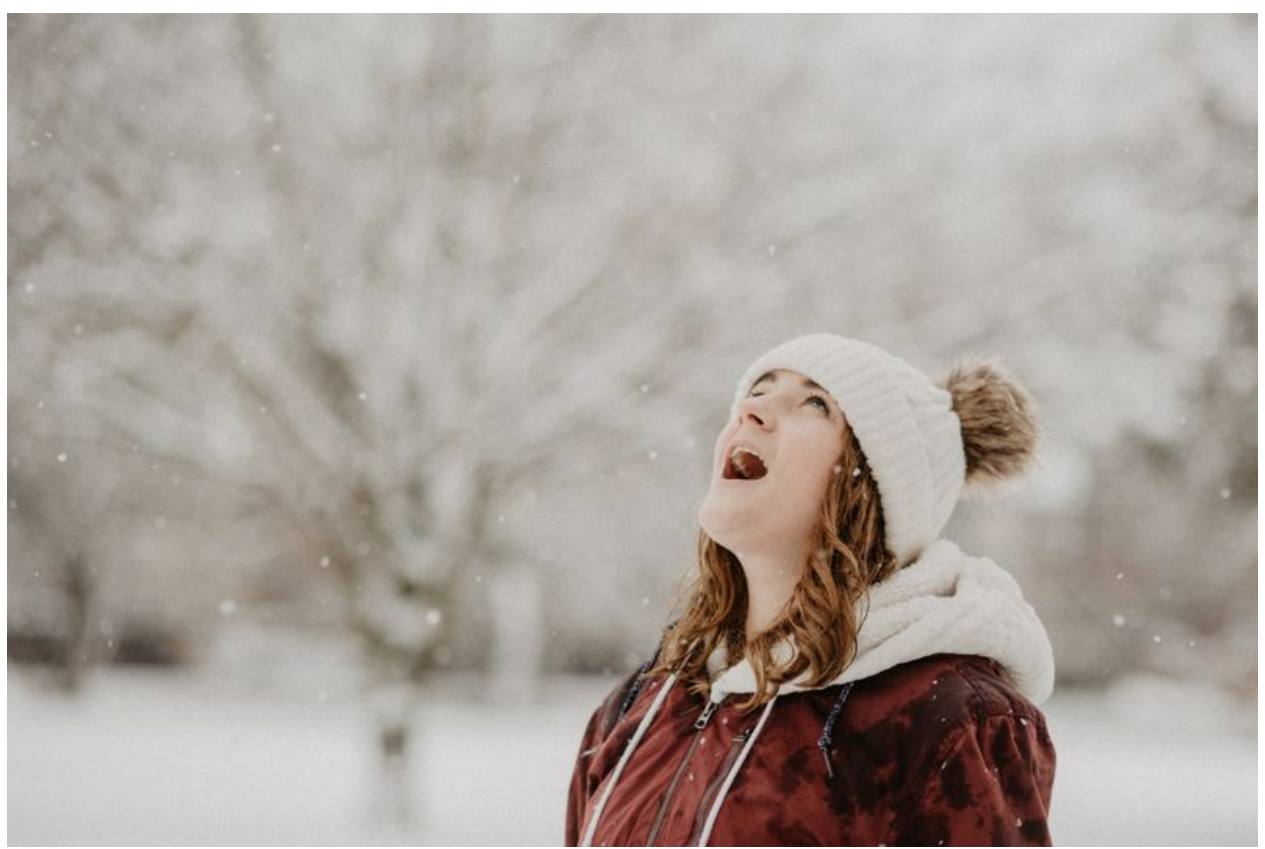

\section{Open science combines the joy of and the passion for new knowledge with a love for learning and the fun of sharing}

"It was opal and this was something I knew, something I could draw a circle around and testify to as being true. While looking at the graph, I thought about how I now knew something for certain that only an hour ago had been an absolute unknown, and I slowly began to appreciate how my life had just changed. I was the only person in an infinite exploding universe who knew that this powder was made of opal. In a wide, wide world, full of unimaginable numbers of people, I was -in addition to being small and insufficient-special. I was not only a quirky bundle of genes, but I was also unique existentially, because of the tiny detail that I knew about Creation, because of what I had seen and then understood" (Jahren 2016).

Universities are not "knowledge factories." Rather, they contain hundreds of knowledge gardens: interfaces to infinite play.

“'Garden' does not refer to the bounded plot at the edge of the house or the margin of the city. This is not a garden one lives beside, but a garden one lives within. It is a place of growth, of maximized spontaneity. To garden is not to engage in a hobby or an amusement; it is to design a culture capable of adjusting to the widest possible range of surprise in nature. Gardeners are acutely attentive to the deep patterns of natural order, but are also aware that there will always be much lying beyond their vision" (Carse 1987). 
Looking at higher education at the national level in the US, every one of the 1.6 million faculty members (now, half of them part-time) adds their own knowledge resources to these gardens. By this they grow the varieties of knowing available in any one place and time: the events that allow giant ideas to emerge.

Students come to campus to acquire their own complex, emergent capacity to be "attentive to the deep patterns" of knowledge. To be clear, students also come to university to embrace their young adult (or pre-career) status in many ways. A lot of learning happens outside the lecture halls. The 2020 pandemic has thrown a sharp light on the value and problematics of on-campus life.

Saying the university nurtures "knowledge gardens" appears as a highly idealized notion. Granted. But it is also important to remember that without its knowledge gardens, a college becomes just another info-plantation, where low-paid precarious labor can be tasked to meet the worker needs of the information industry (sound familiar?): a higher-high school for the technically minded.

A university's knowledge gardens occupy the very center of its core value proposition: they are crucibles for new knowing and wellsprings for creativity and innovation. Additionally, there are many who are looking to carry the knowledge-garden experience down to the middle-school level (why stop there?) (Bereiter and Scardamalia 2016; Dintersmith 2018; Thomas and Brown 2011). Others would add that $21^{\text {st }}$ Century corporations need to adopt a knowledge garden-style outlook (Sinek 2019; Ito and Howe 2016; Hagel and Brown 2008).

There are those who would replace the university's knowledge gardens with infoplantations, which are vastly easier to "manage" and "improve." With some depressing regularity, the metrics for these "improvements" soon devolve into gaming the metrics themselves (Muller 2018). Applying a neoliberal, market-place logic to a university takes the worst of $20^{\text {th }}$ century hierarchical management techniques (calling these "best practices") and attaches them to faculty activities and careers, creating metric ratchets that reward additional "productivity" on a year-to-year basis.

"Universities obviously need to keep good financial books and have systems that are efficient.... But they cannot function properly as capitalist institutions. Their work of labor-intensive, craft-based creation and teaching is non-capitalist. Since capitalism will continue to insist on bottom-line measures of their output, universities will at those times need to be frankly anticapitalist" (Newfield 2016). 
Of course, publicly-funded, higher education and research institutions (colleges, universities, research centers) and their sub-organizations (schools, libraries, research units) have similar personnel and resource management needs as do for-profit corporations. There is plenty of institutional work to be done, budgets to figure and stick to, deadlines to meet, facilities to maintain, the emotional labor needed to keep the workplace convivial: just like any organization.

All workers benefit when open, transparent, consensus-value-guided governance practices apply at their workplaces. But universities are not just like any organization. They cannot be managed through any set of metrics. Open science looks to break the "tyranny of metrics" (Muller, op cit) by expanding descriptions of the value proposition of the university (See Also: Newfield 2016; and Scarcity) to include a broad range of public goods and societal value created from the provident bounty of the academy's knowledge gardens.

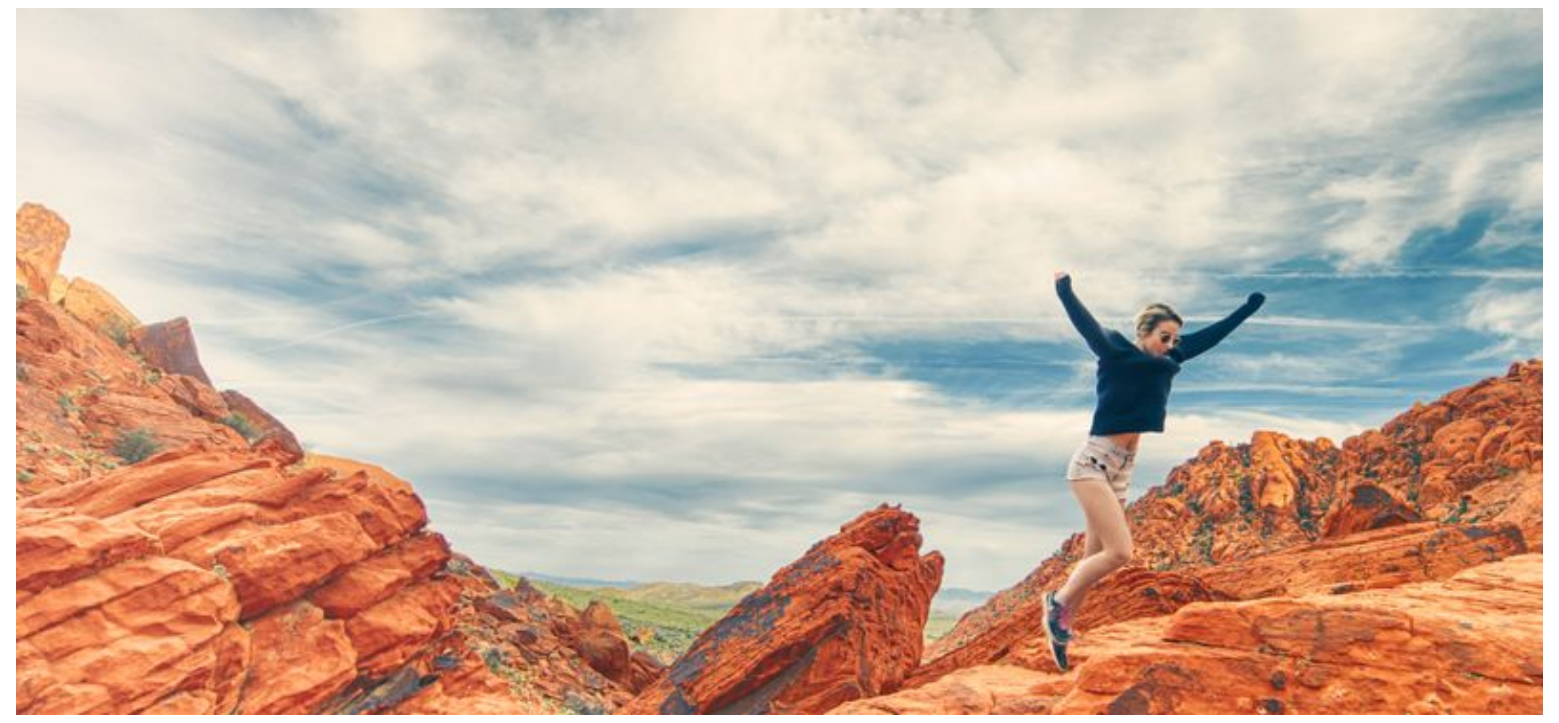

\section{The passion of the open scientist}

"A passion for knowledge, idle curiosity, altruistic concern with the benefit to humanity, and a host of other special motives have been attributed to the scientist"(Merton 1942).

"I didn't realize it at the time, but it was a turning point for me in my life. I had decided to stop chasing the money, and start chasing the passion. I was ready for the next chapter in my life"(Hsieh 2010). 
John Hagel III has recently offered research suggesting that scientists are actually unavailable to be engaged as productive employees (something that university chancellors have long realized). And so, the "community engagement" efforts of college deans, learned societies and academic publishers will necessarily fail, and for a good reason. Perhaps for the best reason.

Hagel notes that "engaged" employees or customers are those who report they are happy with/in their current job, or with the current product/service. They have achieved a static form of satisfaction. From this disposition they can be relied upon to work harder or to buy more. Hagel's argument is supported by a long-term research project he helped lead at the Deloitte Center for the Edge. See: Exploring Passion (Accessed June 8, 2019). See also: Unlocking the Passion of the Explorer (Accessed June 8, 2019).

After decades of thousands of corporate engagement programs across the US, only about $30 \%$ of employees (in their survey) self-report as engaged (op cit). The bulk of the remainder are unhappy for a variety of reasons. Among the serially unengaged are those who come to work or to the marketplace following their own passions.

Hagel is most interested in three passionate dispositions that he claims can add a lot of value to a company in today's emergent economy, well above the return on any engagement program. Combined, these dispositions form what he calls "the passion of the explorer." This description can be extended to include "knowledge explorers": scientists (including librarians and data scientists).

Hagel (op cit) writes:

"This form of passion has three components:

A long-term commitment to achieving an increasing impact in a domain; A questing disposition that creates excitement when confronted with an unexpected challenge;

A connecting disposition that motivates the individual to systematically seek out others who can help them to get to a better answer faster when confronted with an unexpected challenge."

That's a powerful combination. People with the passion of the explorer are never satisfied or happy with what they have accomplished. What excites them is the next challenge on the horizon-it's an opportunity to achieve more of their potential and 
take their impact in the domain to the next level. They are constantly seeking out those challenges and connecting with anyone who can help them address the challenge.

\section{Six rules about passion in the workplace:}

Passion is powerful, and it can shape teams interactions in a undesirable manner without some guidance.

1) Your passion is not a license to be the asshole in your group. You can use your passion to be an asshole with yourself only (well, and with your own research methods). (Sutton 2006; Accessed June 4, 2019).

2) Passion is also not more important than intellectual humility. (Resnick 2019; Accessed June 4, 2019). You can be passionate about learning something new, but don't let this bleed over into being passionate about what you think you already know. That's when you stop learning. Besides, intellectually humble people "possess more knowledge" (Krumrei-Mancuso et al. 2019).

3) Actually passionate people don't say they are. They act passionately, but don't profess this (Schmidt and Rosenberg 2019). They will confess, however, under light interrogation, or a few beers.

4) Having a colleague who is passionate about their work is no excuse to offload extra work on them, simply because they might do this without complaint. Do not abuse passionate workers in this way. They will leave and be passionate in another

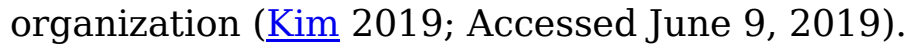

5) During discussions about values and visions, passion needs to give way to humble listening (Schein 2013). Everyone has a voice, each person has a say. You get your time to contribute, but no more. Become passionate about the values the whole team decides are core values.

6) For those who are waiting to "find your passion": Don't wait for it to show up, develop your passion a little more each day. "Urging people to find their passion may lead them to put all their eggs in one basket but then to drop that basket when it becomes difficult to carry" (O'Keefe et al 2018). If there really is nothing in your job that you can connect to with passion, then you might want to ask yourself where else might you belong. 


\section{How to engage the already engaged}

Passionate employees (in Hagel's sense) are predictably unhappy with the status quo. Of course, an original meaning of "passion" is "to suffer." They are necessarily immune from becoming engaged, and, one might guess, reactive to attempts made to engage them. In a 20th Century mode, these are not ideal employees. But the Deloitte study claims that these are precisely the type of employee needed for a 21 st Century corporation.

In the academy, these are the scientists, intellectuals who are passionate about their research, who are eager to teach others, and who are resource-aggressive for any new knowledge they can acquire. Attempts to improve their "engagement" in some form of community will find them refractory in the extreme. Gamification will leave them merely irritated. Emails to them will be deleted unread.

The only community these scientists will really join, and then with some hesitation, are those they own and manage by themselves for their own purposes. They are happiest when they can be connected to others who share their specific objects of study, and even there, their discussions point to unknowns and pain-points in the research process.

How then can these passionate scientists be encouraged to connect, to coordinate their efforts, and collaborate online? What skills and knowledge do academic societies and universities need to acquire to move beyond engagement in order to unleash the collective intelligence of these scientists?

"What many people do not realize is that motivation by fear is indeed highly effective-effective at creating the illusion that goals are being achieved. It is not effective in ensuring that people bring the creativity, good process, and passion needed to accomplish challenging goals in knowledge-intensive workplaces"(Edmonson 2019).

Open science offers a new level of support for the passion of the knowledge explorer. The best environment for this support will be new clubs, research/teaching collectives, and open collaborative networks where small groups of shared-vision/problem-minded scientists work together instead of alone.

\section{What's the final word on Open Science?}

There is no final word here. We are still into beginnings. What is clear is that open science will help science expand and collaborate planet-wide. These new capabilities 
will leverage local public investments by the state and society, rewarding these with new value-added capabilities. Every locale will get more than it gives in this transaction.

Getting to open science will require inserting cultural practices into existing organizations and bootstrapping new ones with open science values and shared governance. You are a culture change agent. But you don't need to change the world, just the corner of it where you work and live. And you are not alone. The best way to start is to get into conversation with others. Real conversation, where you listen more than talk.

Perhaps this Handbook has given you a few things to bring into that conversation. If so, then it's done its job. Pass it on to others, and make a ruckus.

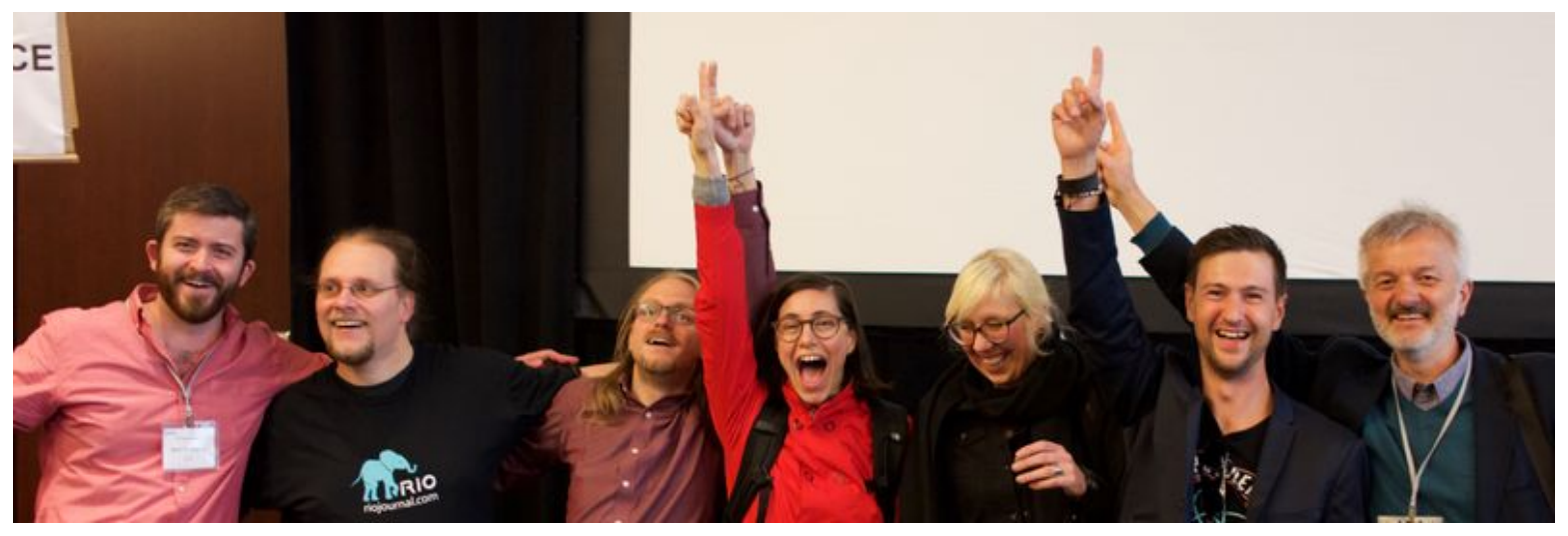

\section{Bibliography: Oppen Scientist Handbook References}

